\title{
Redescription of Ichthyofilaria argentinensis Incorvaia, 1999 (Nematoda: Philometridae) parasite of Merluccius hubbsi (Pisces: Merlucciidae) from Argentina
}

\author{
Juan Tomás Timi ${ }^{1,2}$, Graciela Teresa Navone ${ }^{2,3}$ and Norma Haydée Sardella ${ }^{1}$ \\ ${ }^{1}$ Laboratorio de Parasitología, Departamento de Biología, Facultad de Ciencias Exactas y Naturales, Universidad Nacional de \\ Mar del Plata, Funes 3350, (7600) Mar del Plata, Argentina; \\ ${ }^{2}$ Consejo Nacional de Investigaciones Científicas y Técnicas (CONICET); \\ ${ }^{3}$ Laboratorio de Helmintos, Centro de Estudios Parasitológicos y de Vectores (CEPAVE), Universidad Nacional de La Plata, \\ Calle 2, No. 584, 1900 La Plata, Argentina
}

Key words: Nematoda, Philometridae, Ichthyofilaria argentinensis, Merluccius hubbsi, Argentina

\begin{abstract}
Ichthyofilaria argentinensis Incorvaia, 1999 (Nematoda: Philometridae) is redescribed from type specimens and from parasites collected from the swim bladder of Argentine hakes Merluccius hubbsi Marini, 1933 caught at the Gulf of San Jorge

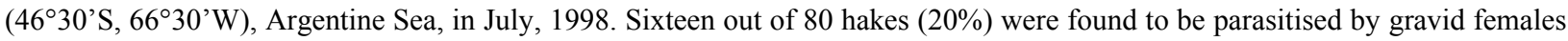
of this philometrid. After revision of both these nematodes and type material, the following differences from the original description of the species were observed: (a) cuticle with fine transverse striations, instead of smooth cuticle; (b) presence of cephalic papillae and a pair of amphids; (c) absence of swellings in the oesophagus; (d) oesophageal gland appendix very large and lobulate rather than small and vermiform, and (d) presence of vulva and vagina. The morphological features given in the redescription allow the confirmation of the identity of I. argentinensis as a valid species and to distinguish it from other members of the genus.
\end{abstract}

The genus Ichthyofilaria Yamaguti, 1935 comprises four species: I. dasycotti Yamaguti, 1935, found in the vicinity of the heart of Dasycottus setiger Bean, 1890 (Cottidae) (Yamaguti 1935) and I. japonica Moravec et Nagasawa, 1985 parasite of the abdominal cavity of Sebastes schlegelii Hilgendorf, 1880 (Scorpaenidae) (Moravec and Nagasawa 1985), both from Japanese waters, I. canadensis Appy, Anderson et Khan, 1985, parasitic in the mesenteries and surface of the liver of Lycodes lavalaei Vladykov et Tremblay, 1936 and $L$. vahlii Reinhardt, 1838 (Zoarcidae), from Atlantic Canadian waters (Appy et al. 1985) and the recently described, I. argentinensis Incorvaia, 1999, from the swim bladder of Merluccius hubbsi Marini, 1933 (Merlucciidae) from Argentina (Incorvaia 1999).

During a parasitological survey carried out on $M$. hubbsi from Argentine waters, philometrid nematodes referable to the genus Ichthyofilaria Yamaguti, 1935 were found. The material examined in the present paper shows a number of morphological differences to those nematodes described as I. argentinensis by Incorvaia (1999); omissions of morphological features, relevant to the description of a new species, were also found in the original description.

Comparisons between the type specimens of $I$. argentinensis and the new material collected from the swim bladder of $M$. hubbsi caught in the same area justify the redescription of the species.

\section{MATERIALS AND METHODS}

A total of 80 specimens of $M$. hubbsi caught by trawler at the Gulf of San Jorge (46 $\left.30^{\circ} \mathrm{S}, 66^{\circ} 30^{\prime} \mathrm{W}\right)$, Argentine Sea, in July, 1998 were examined for parasites. After capture, the fish were stored in ice and carried to the laboratory where they were dissected out and examined.

Swim bladders were excised and the inner tunica was gently removed with the aid of dissection needles. Nematodes were collected and immediately fixed in hot $70 \%$ ethanol and stored in 70\% ethanol (Berland 1984).

Some specimens were cleared in lactophenol and observed under a light microscope. Drawings were made with the aid of a drawing tube. Measurements are given in millimetres (mean followed by range in parentheses), except when otherwise indicated.

Prevalence and mean intensity of infection were calculated according Bush et al. (1997).

Type material (2 paratypes, No. $0065 \mathrm{H})$ of I. argentinensis, deposited in the Collection of Instituto Nacional de Investigación y Desarrollo Pesquero, Mar del Plata, Argentina, was also examined. 

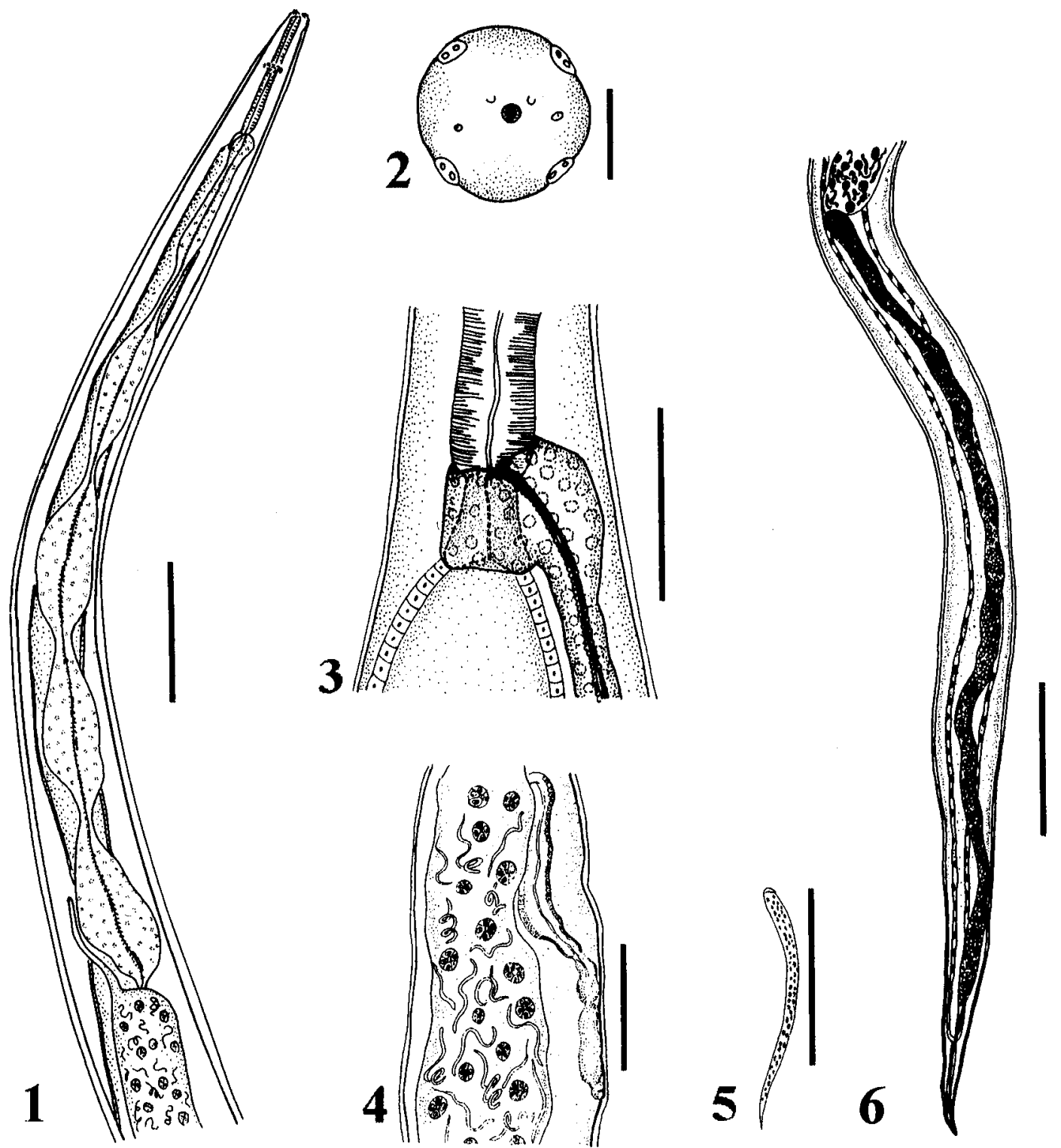

Figs. 1-6. Ichthyofilaria argentinensis Incorvaia, 1999, female. Fig. 1. Anterior end, ventral view. Fig. 2. Anterior end, apical view. Fig. 3. Anterior end, lateral view, detail of oesophageal-intestinal junction and gland appendix. Fig. 4. Vulva and vagina, lateral view. Fig. 5. Larva. Fig. 6. Posterior end. Scale bars: Fig. $1=400 \mu \mathrm{m}$; Fig. $2=20 \mu \mathrm{m}$; Figs. 3, $5=100 \mu \mathrm{m}$; Fig. $4=300$ $\mu \mathrm{m}$; Fig. $6=1 \mathrm{~mm}$.

\section{RESULTS}

Ichthyofilaria argentinensis Incorvaia, 1999

Figs. 1-8

Redescription: Female (description based upon 15 measured gravid specimens), body cylindrical, cuticle with fine transverse striations; anterior end narrowed and bottle-shaped, posterior end conical; body length 31.81 (22.16-38.06); maximum body width 0.63 (0.440.82 ); width at mid-length of narrowed anterior end 0.10 (0.08-0.13). Mouth spherical, surrounded by two asymmetric papillae, four double papillae (two dorsolateral and two ventro-lateral) and a pair of lateral amphids. Muscular oesophagus cylindrical, length 0.51 (0.43-0.60), maximum width $49 \mu \mathrm{m}$ (42-57); glandular oesophagus short, length $76 \mu \mathrm{m}$ (63-86), covered by oesophageal gland with long free appendix, latter very large, length 3.03 (2.50-3.66), maximum width 0.26 (0.18-0.38); ratio appendix length / total oesophagus length 5.17 (3.95-5.96), with five or six lobes separated by deep constrictions and with an evident central duct, lobes usually broadening distally. In females with a not fully developed uterus, the gland appendix is elongated, reaching the anterior end of uterus and overlapping the anterior ovary; in those specimens with uterus filled by embryos and larvae, the gland apendix is turned up and 


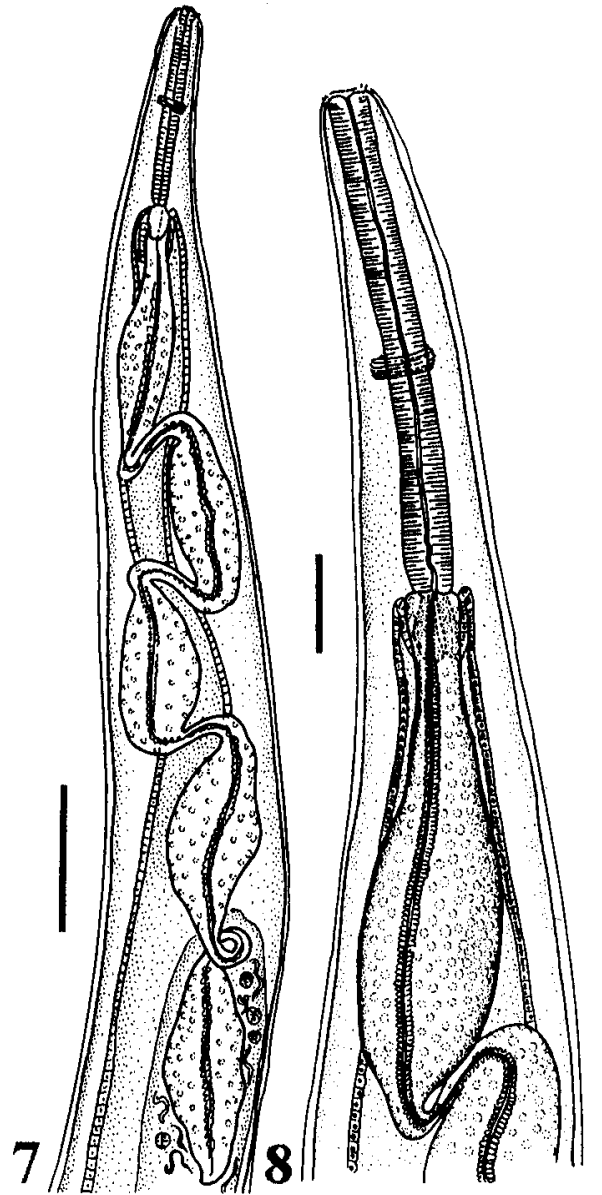

Figs. 7, 8. Ichthyofilaria argentinensis Incorvaia, 1999, female with folded gland appendix and glandular oesophagus protruded into intestine. Fig. 7. Anterior end, ventral view. Fig. 8. Anterior end, ventral view, detail of oesophagealintestinal junction and gland appendix. Scale bars: Fig. $7=$ $400 \mu \mathrm{m}$; Fig. $8=100 \mu \mathrm{m}$.

folded upon itself, the anterior end of the intestine is compressed forward and the glandular oesophagus protrudes into the intestine. Nerve ring encircling the anterior portion of muscular oesophagus, distance from anterior end $0.25(0.19-0.29)$. Deirids and excretory pore not observed. Intestine expanded anteriorly, posterior extremity slender, ending approximately at the level of the posterior ovary end, where it changes into a ligament attached to the ventral wall, limit between intestine and ligament at $0.74(0.48-0.90)$ from posterior body end; anus apparently absent. Vulva situated at 16.55 (11.90-21.48) from anterior body extremity; vagina narrow, directed either anteriorly or posteriorly from vulva. Uteri didelphic, amphidelphic, filled by eggs, embryos and developed larvae; distance from anterior body end $2.73(1.52-4.10)$, from posterior extremity 7.64 (5.37-9.28). Anterior ovary narrow and vermiform to almost absent (depending of the degree of development of uterus), length 0.46 (0.27-0.56), distance from anterior body end (measured from 5 specimens with extended ovaries) 2.19 (1.42-3.13); posterior ovary well developed and straight, length 6.64 (4.50-8.76), attached to a ligament at 0.76 (0.50-1.06) from posterior body end, which reaches the ventral wall of body contiguous to the intestinal ligament. Larvae in uterus with rounded anterior extremity and tapering posteriorly, length $147 \mu \mathrm{m}$ (132-157), maximum width $6.30 \mu \mathrm{m}$ (5.25-7.35), no internal structures were observed.

Male: unknown.

T y p e h o s t: Merluccius hubbsi Marini, 1933 (Argentine hake) (Pisces: Merlucciidae).

L o c a 1 i t y : Gulf of San Jorge (463's, 66 $30^{\circ} \mathrm{W}$ ), Argentine Sea.

$\mathrm{S}$ i t e : Swim bladder, under inner tunica.

$\mathrm{V}$ o u c he r s p e c i m e n s : 5 gravid females deposited in the Colección Zoología Invertebrados del Museo de La Plata (Helmintos). Coll. No. 4800.

P r e vale n c e of i n f e c t i o n : 16 out of 80 hakes $(20 \%)$.

Mean intensity of infection:3.7 (1-15).

\section{DISCUSSION}

After revision of both the paratypes and the specimens collected in the present study, the following differences with the original description of Ichthyofilaria argentinensis (Incorvaia 1999) were observed: (a) cuticle with fine transverse striations; (b) presence of papillae surrounding the mouth and a pair of amphids; (c) absence of swellings in the oesophagus; (d) shape and size of the oesophageal gland appendix, very large and lobulate, rather than small and vermiform, and (d) presence of vulva and vagina.

With the exception of the length of the oesophageal gland appendix, all measurements agree with those of the original description; nevertheless the measurements given by Incorvaia (1999) in the text do not correspond with the scale bars of figs. 1 and 2 of her paper.

In the light of the new morphological evidence observed in the examined material, I. argentinensis can be distinguished from its congeners, I. dasycotti, I. japonica and I. canadensis, by the absence of swellings in the oesophagus and by the shape (lobulate) and size (approximately five times longer than oesophagus) of the oesophageal gland appendix, instead of the vermiform and shorter appendix present in the other three species.

Incorvaia (1999) argues that $I$. argentinensis differs from I. dasycotti by its smaller size and by the ratio body length / muscular oesophagus length; from $I$. japonica because it lacks cephalic projections and from I. canadensis because the gland appendix is free and not included within the intestine. However Appy et al. (1985) refer that in I. canadensis the glandular part of the oesophagus, not the gland appendix, is extended slightly into intestine. It seems to be a confusion 
between the glandular part of the oesophagus and the vermiform appendix (a part of the oesophageal gland) in Incorvaia's description; in all the species of Ichthyofilaria the oesophageal gland appendix extends freely and it is not included in the intestine.

The species redescribed herein also differs from $I$. dasycotti and I. japonica by having vulva and vagina. Ichthyofilaria japonica and I. canadensis also display a folded posterior ovary. Additionally, I. canadensis is the only species of the genus in which the excretory pore was observed. Furthermore, larvae of I. argentinensis are distinctly shorter than those of both I. canadensis (245-257 $\mu \mathrm{m})$ and I. japonica $(195-207 \mu \mathrm{m})$, and wider than those of $I$. dasycotti $(3 \mu \mathrm{m})$. Larvae of $I$. argentinensis differ from microfilarioid first-stage larvae of $I$. canadensis by the absence of nerve ring, excretory pore and cell, genital primordium and anus.

Evdokimova (1973) reports a philometrid nematode belonging to the genus Philonema Kuitunen-Ekbaum, 1933 (as Philonema sp.) in M. hubbsi from Argentina; this finding could be considered as dubious, because representatives of this genus are parasites of freshwater hosts, salmonids in the Holartic and a perciform fish,
Percichthys trucha (Cuvier et Valenciennes, 1840), from a Patagonian lake in Argentina (Moravec et al. 1997). Specimens found by Evdokimova probably belong to Ichthyofilaria argentinensis.

The differences between the original and the present descriptions of $I$. argentinensis do not warrant a change in the taxonomic status of the species; nevertheless, the morphological features given in the redescription allow to confirm the identity of $I$. argentinensis as a valid species and to discriminate it from other members of the genus.

Acknowledgements. The authors gratefully acknowledge Mr. Juan C. Berón for providing the fish samples, Lic. Ana L. Lanfranchi and Luisa Kuba for their assistance during sampling procedures, the authorities of Centro Nacional Patagónico (CENPAT-CONICET), Puerto Madryn, Chubut Province for allowing us to process samples in their laboratories, María Cristina Estivariz for the drawings, and Lic. Inés Silvia Incorvaia for providing the type material. This work was supported by grants of Universidad Nacional de Mar del Plata (Grant No. E117/97) and CONICET (PIP No. 0516/98).

\section{REFERENCES}

APPY R.G., ANDERSON R.C., KHAN R.A. 1985: Ichthyofilaria canadensis n. sp. (Nematoda: Dracunculoidea) from eelputs (Lycodes spp.). Can. J. Zool. 63: 1590-1592.

BERLAND B. 1984: Basic techniques involved in helminth preservation. Syst. Parasitol. 6: 242-245.

BUSH A.O., LAFFERTY K.D., LOTZ J.M., SHOSTAK A.W. 1997: Parasitology meets ecology on its own terms: Margolis et al. revisited. J. Parasitol. 83: 575-583.

EVDOKIMOVA E.B. 1973: Parasitofauna of commercial teleost fishes at the Patagonian Shelf. Thesis, Zoologicheskii Institute, Acad. Sci., USSR, Kaliningrad, 18 pp. (In Russian.)
INCORVAIA I.S. 1999: Ichthyofilaria argentinensis sp. nov. (Nematoda: Philometridae) parásita de Merluccius hubbsi (Pisces: Merlucciidae). Cienc. Mar. 25: 439-444.

MORAVEC F., NAGASAWA K. 1985: Ichthyofilaria japonica sp. n. (Philometridae) and some other nematodes from marine fishes from Hokkaido, Japan. Věstn. Čs. Spol. Zool. 49: 211-223.

MORAVEC F., URAWA S., CORIA C.O. 1997: Philonema percichthydis sp. $\mathrm{n}$. (Nematoda: Philometridae) from the Patagonian smallmouth perch Percichthys trucha (Pisces) from Argentina. Helminthologia 34: 215-219.

YAMAGUTI S. 1935: Studies on the helminth fauna of Japan. Part. 9. Nematodes of fishes. I. Jpn. J. Zool. 6: 338-386.

Accepted 11 September 2000 